\title{
OS DISCURSOS DE LACAN NO HOSPITAL GERAL ${ }^{1}$
}

Carla Borim Mirachi Melo* Luis Flávio Silva Couto"

\begin{abstract}
RESUMO. O objetivo deste artigo é analisar a relação dos discursos com a particularidade da função do praticante de psicanálise em um hospital geral a partir da perspectiva lacaniana. Através do relato de experiências profissionais de um dos autores, foram descritos os laços sociais estabelecidos na instituição hospitalar e problematizadas as questões relativas a esses laços. Adicionalmente, foi realizada uma análise crítica dos modos discursivos e verificou-se que determinados laços sociais são imperativos. A atuação da praticante de psicanálise também foi avaliada e discutida no sentido de se pensar o que poderia ser feito para se estabelecer certo equilíbrio estabelecido entre as discursividades. Concluiu-se que a análise pessoal da praticante foi fundamental para o trabalho realizado por ela no hospital em estudo, pois, sustentada pelo discurso do analista, ela se permitiu transitar pelos discursos radicais e, assim, propiciou condições para que a subjetividade fosse considerada no ambiente hospitalar.
\end{abstract}

Palavras-chave: Psicanálise lacaniana; hospital geral; discursos em Lacan.

\section{THE ISSUE OF HOSPITAL INSTITUTION DISCOURSES FROM THE LACANIAN PSYCHOANALYSIS}

\begin{abstract}
This article analyses the relation between discourses and the particularities of psychoanalysis practice at the General Hospital, from a Lacanian perspective. Through narration of researcher's professional experiences, social connections established in hospital institution were described and respective questions and relevant issues were outlined. Additionally, the different discourse modes were critically reviewed and the conclusion was that some social connections in hospital environment are imperative. The psychoanalysis practitioner was also evaluated and discussed as to what could have been done to establish a balance between discourses. Finally, we concluded that the practitioner personal analysis was fundamental for the work she carried out at the studied hospital. That is because, supported by the analyst's discourse, she allowed herself to transit through radical discourses and, therefore, provide conditions to have the subjectivity considered in the hospital environment.
\end{abstract}

Key words: Lacanian psychoanalysis; general hospital; discourses in Lacan.

\section{LOS DISCURSOS DE LACAN EN EL HOSPITAL GENERAL}

RESUMEN. El objetivo de este artículo es analizar la relación de los discursos con la particularidad de la función del practicante de psicoanálisis en el Hospital General a partir de la perspectiva lacaniana. Por medio del relato de experiencias profesionales de uno de los autores, se describieron los lazos sociales establecidos en la institución hospitalaria y fueron problematizadas las cuestiones relativas a ellos. Adicionalmente, se realizó un análisis crítico de los modos discursivos y se verificó que determinados lazos sociales son imperativos. La actuación de la practicante de psicoanálisis también fue evaluada y discutida en el sentido de pensar lo que podría ser hecho a fin de que un cierto equilibrio se estableciera entre los discursos. Se concluye que el análisis personal de la practicante fue fundamental para el trabajo realizado en el hospital con relación al estudio. Esto porque, sostenido por el discurso del analista, ella se permitió transitar por los discursos radicales y de esta forma logró condiciones para que la subjetividad fuese considerada en el ambiente hospitalario.

Palabras-clave: Psicoanálisis lacaniano; hospital general; discursos en Lacan.

Apoio: CNPq.

Graduada em Psicologia pela Universidade Federal de Minas Gerais, especialista em Saúde Mental e Psicanálise pelo Unicentro Newton Paiva, mestre em Psicologia pela Pontifícia Universidade Católica de Minas Gerais.

\# Professor do Programa de Pós-Graduação estricto sensu da Pontifícia Universidade Católica de Minas Gerais, doutor em Filosofia pela Universidade Federal do Rio de Janeiro, pós-doutor em Psicanálise pela Université Paris 8, membro da Escola Brasileira de Psicanálise - seção Minas. 
O hospital geral é legitimado como um espaço de cura e de reabilitação, sustentado pelos avanços científicos, principalmente os do campo da medicina; contudo, a convivência diária com o funcionamento da instituição hospitalar revela algo além da promessa de tratamentos eficazes e valorização da vida. Isso foi surpreendentemente percebido por um dos autores deste estudo enquanto uma das praticantes de psicanálise $^{2}$ de um determinado hospital geral da região metropolitana de Belo Horizonte - MG.

O ser humano é um ser social por natureza, e como tal, ele é regido por laços sociais. Na instituição hospitalar, vínculos também são estabelecidos e apresentam marcas específicas, porém a compreensão das relações entre os indivíduos nesse ambiente constitui um desafio.

Lacan trouxe avanços consideráveis aos pressupostos psicanalíticos, especialmente no que se refere aos laços sociais. A partir dos conceitos de significante mestre, de cadeia significante, de objeto "a" e de sujeito barrado, ele construiu a sua teoria dos discursos. Ela foi desenvolvida no Seminário XVII "O avesso da psicanálise" (19691970/1992), na "Conferência de Milão" (1978) e em outros textos. Ela propicia uma leitura própria dos enlaçamentos sociais e permite uma maneira peculiar de pensar as relações entre o saber inconsciente, o campo da linguagem e o gozo. Lacan propõe a existência de quatro discursos radicais que organizam, através de matemas, maneiras distintas de relação que regulam o laço social. São eles: o discurso do mestre, o da histérica, o do psicanalista e o da universidade. Ele postula também um quinto discurso, chamado discurso do capitalista, que se relaciona, principalmente, com o consumismo de bens materiais.

O objetivo deste estudo é fazer, por meio da teoria dos discursos elaborada por Lacan, uma análise crítica das relações estabelecidas no contexto hospitalar e avaliar qual deve ser o posicionamento de um praticante de psicanálise nesse ambiente, a partir da experiência profissional de um dos autores deste estudo.

2 O termo "praticante de psicanálise" será utilizado com o objetivo de marcar a distinção entre o trabalho realizado pelo psicanalista em seu consultório privado e aquele desenvolvido pelos profissionais com escuta psicanalítica nas instituições. $\mathrm{O}$ uso desta expressão tem como base o texto "Psicoanálisis puro, psicoanálisis aplicado y psicoterapia" de Jacques-Alain Miller (2001).

\section{A PRATICANTE NO LUGAR DE AGENTE DO DISCURSO DO MESTRE}

Em um ambiente de alta complexidade, como o é o hospital geral, pode-se perceber a presença de várias discursividades e a maneira como elas se relacionam em uma única situação. O exemplo a seguir ilustra uma circunstância em que a praticante teve que ter muita perspicácia para localizar os modos discursivos em questão. Vejamos o caso ${ }^{3}$.

Penélope estava internada havia dois meses e a equipe médica solicitou que a clínica de Psicologia atendesse a paciente. Os motivos da solicitação foram o humor depressivo da doente e a sua agressividade em alguns momentos. Os médicos não viam justificativa para tamanha insatisfação e acreditavam que se tratava de "carência afetiva".

A praticante dispôs-se a escutar a paciente e a sua história. Ela tinha 56 anos, era diabética e tinha cortado seriamente o pé. Tinha ido comprar pão perto de sua casa e escorregara no chão, que estava molhado. Estava preocupada com os dois netos que criava, pois era ela quem sustentava a família com seu trabalho como costureira. Além disso, sentia-se entristecida com a lenta recuperação e com a falta de perspectiva de alta.

Não obstante, diferentemente do esperado, a principal queixa da paciente não era relativa a seu longo período de internação. Sua fala girava em torno da ausência da equipe e da insegurança que sentia em relação aos médicos. Pôde-se perceber na sua fala o medo de uma possível amputação e a possibilidade de perder o pé esquerdo.

$\mathrm{Na}$ percepção da paciente, os médicos tinham "se esquecido" dela. Ela dizia à praticante: "Eles vêm aqui, falam, falam, falam, e não dizem nada. Estou cansada dessa enrrolação". Operando com o discurso da histérica, a paciente explicitava a sua falta e demandava alguém supostamente portador de um significante fálico capaz de produzir um saber sobre o seu sintoma e de lhe tirar do estado de perdição em que se encontrava.

Ao solicitar um senhor capaz de lhe dar respostas eficazes e definitivas sobre os seus problemas, Penélope buscava na figura do outro um médico que se posicionasse como mestre e assumisse o lugar de agente do discurso do mestre; ou seja, ela queria

Para fins de sigilo ético e profissional, vários aspectos que pudessem identificar as pessoas citadas neste estudo foram modificados, entre eles: nome, idade, sexo, estado civil, profissão, grau de parentesco, especialidade médica, doença, período de internação, data e posição do paciente na família (se é pai pode aparecer como filha, etc.). 
alguém que estabelecesse uma relação baseada no autoritarismo e exercesse o poder de mando desconhecendo a sua castração.

Todavia, diferentemente do que era esperado pela paciente, os médicos não ocupavam o lugar de maestria. Eles não se responsabilizavam pela situação e não impunham a sua ordem. Ao invés disso, a equipe operava com outro modo discursivo, a saber, com o discurso da universidade. Ao descentralizar o poder para as várias especialidades, os médicos instituíam a burocracia e, ocupando o lugar de agente como S2, evitavam lidar com as queixas e as demandas da paciente. A saída encontrada para que a subjetividade da paciente deixasse de incomodá-los e tudo continuasse funcionando bem foi solicitar os serviços da Psicologia. Dessa maneira, eles se furtavam de ouvir as lamúrias da paciente e eram solidários com a discursividade proposta pela instituição.

A conduta da praticante foi a de acolher Penélope nas suas angústias e a de propiciar condições para que alguma mudança ocorresse na sua posição subjetiva. Percebendo a demanda histérica e o convite para ocupar o lugar de maestria, a praticante optou por se posicionar como mestre. Sabendo das atividades da paciente como costureira e como ela se sentia importante ao prover a casa financeiramente, a praticante lhe disse: "Não sabia que você costurava com os pés. Onde estão os seus bordados?’. Algo desconcertada, Penélope respondeu: "É mesmo, eu não tinha pensado nisso!". Com tranquilidade, a praticante se despediu da paciente e disse que voltaria em outro momento para vê-la.

Com essa conduta a praticante ocupou o lugar de agente no discurso do mestre e deu uma ordem à paciente por meio de uma comunicação latente: borde! Naquele instante, consciente da sua posição, ela optou por fazer um semblant de S1 e assumiu a posição de alguém que, supostamente, detinha a solução para o problema de Penélope. Isso só foi possível a partir do discurso do analista e do lugar da praticante enquanto objeto "a". Destituída de qualquer intenção de dominação, ela estava consciente da sua barra estrutural, de sua castração e de sua impossibilidade de tudo governar. Assim, a praticante apenas "fez de conta" que era o mestre tão demandado pela paciente, e isto propiciou as condições para que uma circularidade entre os discursos acontecesse.

Nessa situação, o posicionamento da praticante foi condizente com o conceito de transférisation ou "transferização" desenvolvido por J-R. Freymann (comunicado em palestra, 16 de março, 2008). Segundo o autor, a "transferização" refere-se a um esforço do analista para que algo da ordem da transferência faça-se presente. Seria como se o praticante "preparasse o terreno" ou "adubasse a terra" para que o "crescimento de uma plantação" fosse possível. Trata-se de um primeiro passo a ser dado pelo analista para que certo suposto saber do sujeito seja nela depositado.

Ao utilizar o significante "bordado", a praticante tentou tocar a paciente nas suas questões, para que algum efeito subjetivo ocorresse na sua posição de demandante queixosa. Dessa maneira, mesmo operando com o discurso do mestre, a intervenção foi psicanalítica, pois a colocação da praticante tinha como foco a subjetividade da paciente e estava em consonância com a ética do desejo. Ela não tinha o intuito de dominar a paciente, nem de submetê-la incondicionalmente à sua autoridade. Ao contrário, a praticante tinha clareza do lugar que realmente ocupava na ocasião, qual seja, o lugar de semblant do falo simbólico, e nada mais.

Em relação à equipe médica, a praticante contatou o endocrinologista que constava no prontuário médico como responsável pelo caso de Penélope. Ele disse que a recuperação da paciente seria mesmo lenta e que não havia motivos para o medo de perder o pé. A praticante lhe falou sobre os receios da doente de uma possível amputação e de como ela se sentia insegura quanto à condução do seu tratamento. Muito educadamente, o médico argumentou que eram muitos os pacientes, que o tempo era curto, que ele andava muito ocupado e que, por isso, os residentes o ajudavam. Aparentando bastante cansaço, falou que conversaria com a paciente quando "tivesse um tempinho".

Ao discutir o caso com o médico, a praticante pôde perceber que ele operava com o discurso da universidade, mm modo discursivo caracterizado pelo S2 no lugar de agente, típico da burocracia e dos protocolos. Ele não se posicionava com firmeza e parecia concordar com o que quer que fosse, no intuito de assegurar que o seu trabalho não fosse interrompido. Agenciando o modo discursivo a partir do lugar de saber, ele explicou a sua conduta e manteve uma postura de neutralidade. Como um burocrata, foi "politicamente correto" e evitou malestares.

Não obstante, é importante ressaltar a justificativa do médico para a sua conduta e o cansaço por ele apresentado. Apesar de operar com o discurso da burocracia e colaborar com um modo de laço social muito valorizado no espaço médico, algo de submissão estava presente na sua fala. Ao queixar-se do excesso de tarefas e da falta de tempo para cumprir 
as suas obrigações, ele falava de uma segunda posição. Curiosamente, ele ocupava o lugar do outro nessa mesma discursividade e se posicionava como o $a$-estudante, incapaz de cumprir as tarefas propostas por um S2 exigente.

Assim, é interessante notar a diferença existente entre o lugar ocupado pelo médico na relação com a paciente e na sua relação com o discurso institucional. Apesar de ambos os laços sociais serem regidos pelo discurso da universidade, há uma divergência importante entre eles no que tange ao posicionamento do médico. No que diz respeito ao vínculo com Penélope, o endocrinologista ocupava o lugar de agente e instituía o saber burocrático; mas na relação com o discurso institucional, ao contrário, ele ocupava a posição de outro, enquanto objeto "a”. Essa situação revela que se, por um lado, o médico colabora com o discurso vigente, por outro, ele também está submetido aos seus ditames.

Retomando o caso, depois de dois dias sem ver a paciente, a praticante foi ao seu quarto. Encontrava-se menos queixosa e um pouco mais disposta. Ela relatou ter pedido a sua filha que levase linhas e tecidos para o hospital, pois aproveitaria o tempo para fazer alguns bordados. Disse que o endocrinologista estivera lá e que a possibilidade de amputação era muito remota. A resposta a deixara muito aliviada e satisfeita e as reclamações de falta de atenção e de compromisso dos profissionais com o seu caso haviam diminuído. Após algumas semanas ela teve alta hospitalar.

\section{O PRATICANTE SUSTENTADO PELO DISCURSO DO ANALISTA}

É importante apontar que o trabalho realizado pela praticante de psicanálise no hospital é diferente daquele realizado por um psicanalista no consultório privado. Na clínica particular, o analista disponibiliza a sua escuta e permite que algo da ordem do inominável se revele para o sujeito. Ele propicia condições para que alguma coisa da enunciação se faça presente e aposta no valor da produção do sujeito (\$), independentemente de seu conteúdo. Trata-se de possibilitar que o analisante se dê conta de que é escutado por alguém que está disposto a ouvi-lo. Sustentado pelo discurso do analista, ele permite o giro e a circularidade entre os outros discursos radicais. Na posição de objeto "a", ele não se envolve em nenhuma espécie de disputa por poder. Depois de passar por um processo de destituição subjetiva, ele é capaz de sustentar o discurso do analista, transitar pelas discursividades e apenas "fazer de conta que".
Diferentemente, o hospital geral apresenta características específicas que impedem o estabelecimento de uma transferência analítica tal como no consultório privado; mas isto não quer dizer que não haja trabalho possível para o praticante na instituição hospitalar. Como visto no exemplo acima, a praticante encontrou um recurso interessante para aqueles que pretendem exercer a escuta psicanalítica no ambiente médico.

Diante dos desafios enfrentados no hospital geral, a praticante deu-se conta do valor da sua análise pessoal, especificamente em relação às discursividades. Ela percebeu que quanto mais perto do seu final de análise e quanto mais perto de se colocar como objeto "a" na construção e na travessia de sua fantasia, mais facilmente ela seria capaz de transitar pelos discursos radicais. Ocupar os lugares de agente nos discursos do mestre, da histérica, e mesmo da universidade, torna-se um recurso de grande valia para o estabelecimento de algo referente à atuação psicanalítica no espaço hospitalar. Ao fazer semblant de S1, S2 e mesmo de \$, sem se identificar com eles, a praticante pôde criar um ambiente favorável para que alguma mudança acontecesse na postura subjetiva do sujeito envolvido com o cenário hospitalar.

Quanto mais próximo do seu final de análise, isto é, quanto mais próximo do "vazio inominável de seu ser de objeto", mais claros estão para a praticante os aspectos de semblant das posições de agente (Quinet, 2009, p. 105). Com isso, não lhe é difícil perceber que, no hospital geral, pode-se fazer semblant, enquanto agente, de qualquer um dos significantes discursivos, avaliando a cada momento a pertinência de cada posição, assumindo-a sem a ela se identificar. Isso é feito no caso a caso, para o encontro das melhores soluções possíveis.

$\mathrm{O}$ praticante não precisa operar somente com o discurso do analista; ele o faz tomando por base o que Lacan aponta quando afirma que ele mesmo não ocupa sempre o lugar do analista. Nas suas palavras: "Mas, enfim, esse discurso analítico, é necessário, pois, não esquecer, queiram me desculpar se eu certamente nele não me coloco." (Lacan, 19731974/2009, p. 13, tradução nossa). Disso podemos inferir que, enquanto "a", o praticante pode se permitir transitar pelos discursos radicais. Ele, sempre mantendo a operação do discurso do analista, pode fazer semblante de S1 de um discurso do mestre, de $\mathrm{S} 2$ de um discurso da universidade e, mesmo, quando convier à situação, de $\$$ de um discurso histérico.

No exemplo acima, ao operar com o discurso do mestre, a praticante instituiu condições para que algumas mudanças ocorressem na posição subjetiva da 
paciente, e isso de fato aconteceu. Fazendo semblant de S1, a praticante supostamente ocupou o lugar de significante mestre. Com uma espécie de postura superegoica, utilizou o poder de mando: "Borde! Faça alguma coisa para mudar a situação". Em vez de fixarse nesse lugar e instituir a discursividade de maestria, a praticante apenas "fez de conta" que tinha a solução para o seu problema. Ao contrário do mestre que desconhece a sua castração, durante toda a situação a praticante esteve consciente da sua hiância.

Dessa maneira, é possível que a praticante opere com o discurso do mestre, desde que saiba recolocar o objeto "a" no lugar de agente, tal como constituído pelo discurso do analista. De acordo com as circunstâncias, transitar pelo discurso da mestria, ou fazer semblant de S1, pode ser essencial para a valorização da subjetividade ou para o exercício de determinada função. Silva (2006) reforça esse posicionamento e discorre sobre essa possibilidade em relação ao trabalho realizado pelo analista gestor no serviço público de saúde mental. Na sua dissertação de mestrado, ela aponta a importância da circularidade entre os modos discursivos e ressalta o cuidado que o praticante deve ter ao, supostamente, ocupar o lugar de agente enquanto significante mestre. Nas suas palavras, o analista:

É aquele que, mesmo ocupando o lugar dominante no discurso do mestre, não se identifica ao imperativo, não se identifica com esse lugar de domínio e imposição. Ele sabe que esse lugar e esta função são um semblante e quem nele se situa está castrado (Silva, 2006, p. 132).

Historicamente, a instauração do discurso do mestre é de responsabilidade do médico, e o posto de autoridade é ocupado por ele no hospital geral. Como representante do saber científico, ele é considerado uma figura de respeito, sendo capaz de resolver as angústias dos pacientes. Segundo Clavreul (1983), os médicos impõem a sua ordem e ditam as suas normas ao prescreverem os tratamentos para os doentes. No seu dizer: "a prescrição médica é um enunciado dogmático: coma isso, não beba aquilo, não fume, repouse..." (Clavreul, 1983, p. 14). Trata-se de um modo discursivo baseado no autoritarismo, em que o médico se dirige ao paciente como se dirigiria a um subalterno, a um seu escravo, desconsiderando sua posição subjetiva.

De fato, o médico ainda mantém o seu status de poder e traz consigo certo prestígio especial em relação a outros profissionais. Por outro lado, é interessante ressaltar que algo desse lugar de superioridade parece vir se modificando no contexto contemporâneo. No caso descrito, o representante da medicina não se posicionou como mestre, frustrando a paciente, que esperava dele tal postura - algo que não é difícil de acontecer no contexto médico. Atualmente, na época do declínio do pai (Santiago, 1998), na época do Outro que não existe (Miller, 2005), o médico, no ambiente hospitalar, parece não querer - ou não conseguir - operar com o discurso do mestre e sustentar o lugar de senhor, tal como em outras épocas (o que não é, de todo, ruim).

Dessa forma, uma mudança importante parece acontecer no contexto do hospital geral contemporâneo. Os vários protocolos a serem seguidos, o imperativo da burocracia e a pressão para que tudo seja feito com eficácia e rapidez, parecem assumir um lugar de prioridade na instituição médica. $\mathrm{O}$ discurso da universidade tem revelado a sua força e levado a que todos os envolvidos com a instituição sintam o seu poder, inclusive os médicos. Se, por um lado, estes têm operado com essa discursividade e têm contribuído para o bom funcionamento da instituição, por outro, eles também têm estado submetidos aos seus imperativos. Se antes eles instituíam o discurso do mestre e representavam a figura paterna, hoje eles já não ocupam tal lugar como anteriormente. Semelhantemente a todos os envolvidos com o hospital geral, os médicos também têm os seus aspectos subjetivos desconsiderados e sentem as características negativas do discurso da universidade.

De fato, o discurso da universidade apresenta questões complexas no que se refere à subjetividade (Lemoine-Luccioni, 1998). Sem dúvida, o crescimento de tal modo discursivo na contemporaneidade deve ser alvo de estudos e reflexões; porém isso não significa que esse discurso radical não tenha o seu valor e que não possa ser operado em nenhuma ocasião. Vejamos uma circunstância em que a praticante fez semblant de S2 e ocupou o lugar de agente do discurso da universidade.

\section{A PRATICANTE NO LUGAR DE AGENTE DO DISCURSO DA UNIVERSIDADE}

Marta, muito humildemente, solicitou à praticante que the explicasse a alimentação de seu pai. Constrangida, pediu desculpas por fazer tal pergunta. O senhor. Heitor tinha 85 anos e sofria do Mal de Alzheimer. Havia tido uma piora importante desde alguns dias e isso causara a sua internação. No dia anterior o médico dissera rapidamente à filha que seria 
necessário fazer uma gastrostomia no paciente. Por não entender o que seria tal intervenção e estar inibida ante a postura de superioridade do plantonista, foi para casa com dúvidas e com preocupações relativas à gravidade da cirurgia. No dia seguinte a filha do paciente perguntou à praticante $\mathrm{o}$ que era a tal chamada gastrostomia.

A conduta da praticante foi a de responder de forma simples o que era o procedimento. Disse que seu pai não tinha condições de se alimentar pela boca porque ali estava um tubo que o ajudava na respiração. Dessa forma, a gastrostomia seria uma cirurgia para colocar um segundo tubo que levaria a alimentação diretamente para o seu estômago. Depois da breve explicação, a praticante encorajou-a a buscar esclarecer suas dúvidas com o médico. A postura adotada pela profissional está de acordo com a visão de Granha (2000), segundo a qual emprestar palavras ao indivíduo permite que ele possa dar sentido ao que está vivendo. Fornecer explicações sobre o porquê da internação ou de tantos aparelhos pode ressituá-lo no seu discurso, apesar da possibilidade iminente de perda.

Assim, nessa ocasião, a praticante supostamente ocupou o lugar de S2 e se dirigiu ao outro - no caso, à filha do paciente - como se ela fosse o objeto "a". Ao agenciar a relação a partir da posição de saber, operou com o discurso da universidade. Cumpre, porém, ressaltar que se trata de uma suposta ocupação, porque ela somente assumiu o lugar de semblant de S2. Ela sabe que, de fato, não detém o saber total e burocrático conforme proposto por essa discursividade, e que ensinar como um pedagogo não é a sua função. Por esse motivo, tal posto foi ocupado apenas circunstancialmente. Nesse momento ela fez de conta que possuía o tudo-saber para propiciar condições para que algo de uma transferência (ou de uma transferização no sentido anteriormente apontado) pudesse ser estabelecido - estratégia possível à praticante se, e somente se, ela estiver consciente de que se trata apenas de fazer semblant, de criar um certo "faz de conta que".

Dessa maneira, é pertinente apontar que essa conduta não é incoerente com os pressupostos psicanalíticos; pelo contrário, a postura adotada pela profissional nessa ocasião está de acordo com o seu lugar enquanto praticante de psicanálise, qual seja, o de representar alguma coisa do lugar de objeto causa de desejo. Durante todo o momento ela tem como referência a posição de objeto "a" que diz de um resto, de um dejeto. Ela apenas transita por outras discursividades de forma a favorecer um giro no laço social e fazer com que o sujeito lide de outra maneira com as suas questões.

Nessa circunstância, após o esclarecimento conciso, a praticante convidou Marta a falar sobre o que a afligia. A paciente falou sobre o carinho que sentia pelo pai e sobre o medo de perdê-lo. Apesar do longo período da doença, estava acostumada com a sua presença em casa e a iminência de morte despertava-lhe um grande sentimento de desamparo. É importante apontar que, nesse momento, a praticante deixou de fazer semblant de $\mathrm{S} 2$ e passou a ouvir a jovem em uma posição que se aproximava, de certa forma, do lugar de semblant de objeto "a", do lugar de objeto causa de desejo, tal como no discurso do analista. Ela não se manteve no posto de semblant de S2 para que a filha do paciente não tivesse a sua subjetividade desconsiderada e não se sentisse incapaz de lidar com as suas próprias questões. Isso era o que frequentemente acontecia através da postura dos médicos, os quais muitas vezes se colocavam como professores detentores do saber absoluto.

\section{CONSIDERAÇÕES FINAIS}

Concluimos que, sustentada pelo discurso do analista, a praticante pôde transitar pelas discursividades como uma forma de fazer valer aspectos da subjetividade, uma subjetividade que, de certa forma, vem sendo cada vez mais descartada nas sociedades contemporâneas, diante da grande influência do discurso universitário, e mesmo do capitalista. Na posição de objeto "a", a praticante se permite circular pelos discursos radicais, fazendo semblant, a fim de favorecer a escuta do um a um. Nos casos acima, as alternativas encontradas pela praticante foram a de fazer semblant de S1, de S2 e mesmo de "a", ao operar com o discurso do mestre, com o discurso da universidade e com o discurso do analista. Tais condutas propiciaram-lhe condições para lidar com as angústias dos pacientes de maneira diferente daquela do corpo clínico. Nos casos relatados, estes tiveram os seus aspectos subjetivos considerados e conseguiram lidar de outra forma com as suas questões. Assim, foi fundamental que a praticante soubesse fazer operar o objeto "a" no lugar principal, para que ela tivesse alternativas no exercício da sua profissão e fizesse valer a ética do desejo afinal, cabe ao praticante posicionar-se da melhor maneira possível, de acordo com as circunstâncias, de forma a favorecer a escuta do um a um. 


\section{REFERÊNCIAS}

Clavreul, J. (1983). A ordem médica: poder e impotência do discurso médico. São Paulo: Brasiliense.

Granha, M. T. (2000). Reflexões sobre a prática do psicanalista no hospital geral. In M. D. Moura (Org.), Psicanálise e hospital (pp. 83-91). Rio de Janeiro: Revinter.

Lacan, J. (1978). Discours de Jacques Lacan à l'Université de Milan le 12 mai 1972, parudans l'ouvrage bilingue: Lacan in Italia 1953-1978. In I. Lacan, La S. Milan, (pp. 32-55). (Trabalho original publicado em 1972).

Lacan, J. (1992). O seminário - Livro XVII: o avesso da psicanálise. Rio de Janeiro: Jorge Zahar. (Trabalho original publicado em 1969-1970).

Lacan, J. (2009). Séminaire 21 - Les non-dupes errent. Recuperado em 21 de outubro de 2009, de http://gaogoa.free.fr/Seminaires_HTML/06-

DI/DI01071959.htm. (Trabalho original publicado em 1973-1974).

Lemoine-Luccioni, E. (1998). Travail d'amour. Paul Déroulède: Collection Trames - Actualité de la Psychanalyse.
Miller, J. A. (2001). Psicoanálisis puro, psicoanálisis aplicado y psicoterapia. Recuperado em 01 de novembro de 2009, de http://www.cdcelp.org/freudiana/J.A_Miller_1.PDF.

Miller, J. A. (2005). El Otro que no existe y sus comités de ética. Buenos Aires: Paidós.

Quinet, A. (2009). As 4+1 condições de análise. Rio de Janeiro: Jorge Zahar.

Santiago, J. (1998). O declínio da função paterna, sua repercussão na família e a consequência na família. Opção Lacaniana, 21, 24-27.

Silva, M. E. (2006). O analista gestor: um estudo sobre a prática de um analista de orientação lacaniana como coordenador de um serviço público de saúde mental. Dissertação mestrado, Pontifícia Universidade Católica de Minas Gerais, Belo Horizonte, BH, Brasil.

Recebido em 24/03/2010

Aceito em 31/05/2012

Endereço para correspondência: Carla Borim Mirachi Melo. Rua Porto Carrero, número 91, apto 501, Bairro Gutierrez, CEP 30441-185, Belo Horizonte-MG, Brasil.E-mail: carlamirachi@yahoo.com.br. 